\title{
HOFSTEDE'S CULTURE VALUES SURVEY IN ALBANIAN PRIVATE HOSPITALS
}

\author{
Irma Gjana \\ igjana09@epoka.edu.al \\ Xhimi Hysa \\ ${ }^{1}$ Faculty of Economics and Administrative Sciences \\ Epoka University \\ Rr. Tiranë-Rinas, Km. 12, Vorë, Tirana, Albania, 1032
}

\begin{abstract}
The purpose of this paper is to highlight the changes that Albanian cultural dimensions' scores have undergone over time. Hofstede's Value Survey Module 2013 (VSM 2013) has been applied to examine the six dimensions of culture; power distance, individualism, masculinity, uncertainty avoidance, long term orientation and indulgence. The survey data $(\mathrm{N}=387)$ was collected in the two largest private hospitals in Albania. Globalization, technological developments, economical flourishing and crisis, war and peace, influence the shifting of national cultural dimensions' scores toward negative or positive values [1]. In this study we aim to show the shifting of Albanian culture value scores in time, and compare the results with the ones, predicted by the researchers of the field. The results obtained show a negative shift on Albanian culture dimension score of power distance, individualism, long term orientation and indulgence, and a positive shift on masculinity and uncertainty avoidance values. Implications for researchers of the field are discussed in the paper.
\end{abstract}

Keywords: Hofstede, Albania, private hospitals, culture dimensions, shifting of scores.

DOI: $10.21303 / 2504-5571.2020 .001325$

\section{Introduction}

It has been a long time since the study of national culture has attracted the attention of researchers [1-7]. The study of cultural values in the managerial endeavors has gain importance over time since it is seen as the starting point of reference to understand changes and enable the adaptation of managerial systems to increase outcomes. This explains the importance that managerial study experts give to the understanding of the dimensions of culture, since they associate culture with the success or failure of businesses $[2,6,8-10]$.

Under the influence of globalization, the interaction of cultures is very tangible [10-13]. It is already impossible to think of an interaction between countries and companies without being open to cultural differences and commonalities. Even in a more micro aspect, within one country, we expect a significant impact of technological developments, free movement of people and culture interactions in the reshaping of cultural values of individuals.

Understanding the culture and its dimensions will help us understand the people's attitudes, beliefs and way of behavior. The understanding of the above items will help us develop new forms of communication and interaction in order to get the best results without causing unnecessary conflicts.

Although the term of culture has had different forms of explanation, according to the field of study [14], not all researchers have agreed on simplification of this term into dimensions [2]. However, many quantitative studies have been conducted and have measured the dimensions of culture, as they have defined them. Some of these studies are the Hofstede's framework in 1980's and 2001, GLOBE in the 1990's, Trompenaars in 1993, and World Values Survey in 1990 and 1997 [15].

The authors of this research paper have preferred to use as a measurement tool the framework, developed by Hofstede. Despite the limitations and criticism that Hofstede cultural framework has received $[5,16,17]$, mentioning that the study was conducted quasi 40 years ago and national cultures has changed since then $[1,15]$, fact that we are going to the question, following this study. The simplicity of the application of dimensions, the possibility to easily access to a large data set are some of the reasons why the Hoftede 6-dimension cultural method is used largely by 
researchers $[18,5]$. We must specify that Hofstede's work includes research on Albanian national culture as well. The above submitted facts are some of the reasons for choosing Hofstede's 6-Dimension cultural model as the research method for the development of this research.

In order to collect the data and to examine empirically the Albanian cultural dimension's scores, we have chosen to use the Hofstede's Values Survey Module 2013. By means of VSM 2013 we measure the following six cultural dimensions:

1) Power Distance (PDI);

2) Individualism (IDV);

3) Masculinity (MAS);

4) Uncertainty Avoidance (UAI);

5) Long Term Orientation (LTO);

6) Indulgence versus Restrained (IVR).

The VSM 2013 has been delivered in person to a large number of two biggest private hospitals in Albania, American Hospital and International Hospital Hygeia, and results of scores of each dimension are discussed as implications for researchers of the field.

The contribution of this study includes the added value to the Hofstede's cultural dimensions framework, to the missing studies on this field in the region and especially in Albania, and finally by presenting the data, collected in Albania, we shed light and respond to the assumptions that cultural value scores change through time according to the movement shift, foreseen from the researchers [1, 15].

In this study we are not going to compare the findings with another country, we only aim to show the shift of values in time, explained by the data, collected in the research and discuss the possible impact factors on this score shift.

The aim of this study is to show the changes that Albanian cultural dimension scores have undergone over time.

\section{Materials and Methods}

\section{1. Theory and Background}

The definition of culture has been presented in many diverse forms. According to [14], definitions of culture change in accordance of the difference of the field of study, elaborating this variable. Scholars believe that culture is the breadth of common values, beliefs, rules, and expectations that characterize groups of people and through which norms of behavior and roles are produced [2-6].

The researchers states that the new era manager's job has changed due to the change of the world into a global village [19]. They strongly believe that managers need to understand the culture, geography and religion that shape the people they work with [3, 4, 20, 21]. The workforce diversity apprehension is needed, for an effective workout. If culture and its hidden impacting force within individuals are understood, than problematic behaviors and situations within an organization can easily be solved. Understanding the differences helps to find new ways of adaptation for optimal solutions [2].

The cultural patterns show differences in accordance with the social environment they were learned or developed. If we perceive our minds as giant software as Hofstede originally did [1], than culture differences are changes in 'the collective programming of the mind' of different individuals, groups and societies. The data collection that everyone has in its software shows a close relation and it is shaped according to the environment, someone grew up in. Family, school, and organizations are some of the environments, where the process of this 'collective programming of mind' is realized [1]. The researchers have presented the culture as a structure in layers, where the outer layers are influential and changeable, while the nucleus is more resistant to change and it is precisely the measurements, made at this point, that give us the right data about a country's cultural dimension value scores $[1,2,22]$.

Different cultural studies have been developed through time, elaborating and measuring the dimensions of culture according to methods and data, collected over a wide period of time and in a very large number of populations. 
Hofstede started the elaboration of his model of cultural dimensions in 1967-1969, while he was enabled to study on a wide-ranging amount of survey data of the people, working in the local subordinate companies of a large multinational corporation: International Business Machines (IBM) $[1,6,13]$. The first model was composed only from four dimensions and only after the addition of two more dimensions, one in 1991 and the other in 2007 [1], arrived in its full form, that of six dimensional cultural model [22]. The completed cultural value structure consists of six cultural dimensions: Power Distance (PDI), Individualism (IDV), Masculinity (MAS), Uncertainty Avoidance (UAI), Long Term Orientation (LTO) and Indulgence versus Restrained (IVR).

Each of these dimensions is measurable according to the specifications they have and are used in the comparison of different cultures.

In every country there exist inequalities. Some people have more power than other people do, some are wealthier, some are stronger, and some are more educated than others, and so on. The difference between countries and societies stands in the way these inequalities are handled. This attitude of the less powerful members of society in expecting and accepting the distribution of inequalities is named Power Distance (PDI). We must emphasize that power distance is one of the most attractive cultural dimensions, studied from the researchers [5]. The understanding of power distance helps us understand leader's potential way of acting and followers' expectation.

Individualism (IDV) shows the loose ties of the interpersonal ways of communication and interaction of societies. In such societies the individual and the individual interest dominate over the groups and group's interests.

Masculinity (MAS) demonstrates the way countries deal with gender roles. A masculine society is explained as societies, unfolding masculine cultural values, that shelter and transcends strength, aggressiveness, closed to what is different and new, focused on material gains and ego-enhancing environments. A society, caring feminine cultural dimension, is a caring, modest, integrative, focused on quality of the life, where effacement of ego prevails [1].

Uncertainty Avoidance (UAI) shows the magnitude of confrontation with the unknown and risk taking decisions in a society $[1,10]$. In uncertainty avoiding countries, just as the name suggests, what is uncertain and different is not welcomed, must be avoided and sometimes must be fought.

Long Term Orientation (LTO), as mentioned in the explanation of the development of 6 dimensional model of national culture, is a dimension, added later to the first four dimensional model, constructed by Hofstede. It is a dimension, developed by Michael Bond as a result of the analysis of the Chinese Value Survey [1]. The focusing on future results rather than actual outcomes is what long term orientation cultural dimension measures. In a more concise way, long term orientation shows the prevalence of desire of future result over immediate outcomes in individuals [10].

Indulgence versus Restrained (IVR) is the most recent dimension, joining the cultural model, developed by Hofstede. It is a dimension, developed by Michael Minkov, derived from the World Values Survey. According to the dictionary meaning, indulgence is the permission you give to yourself to experience something enjoyable. The main key items, related with indulgence, are the subjective feeling of happiness, importance of free time and life control perception [1].

Globalization, technological developments, economical flourishing and crisis, war and peace, influence the shifting of national cultural dimensions' scores toward negative or positive values [1]. Despite the shifts in the cultural values scores, the stability of national cultural values between countries, in respect to one another, is evident and explained by researchers from the prism of culturalism [15].

According to the research studies, dealing with the cultural dimensions mentioned above, the values of societies are rooted in time. Despite the ongoing changes worldwide, these values rarely change. Even if they show changes, the differences between the scores of the countries remains the same, showing a clear stability of scores through time. The future of these dimensions shows an increasing tendency into low power distance, individualism and indulgence worldwide. No or very small changes are perceived about masculinity and long term-orientation. While uncertainty avoidance cultural dimension shows a wave like movement, increasing and decreasing through time in accordance with other factors, such as war and peace, economic crises and stability. Despite the minor changes in the scoring of these dimensions, the position of countries according to one 
another remains the same, showing that cultural values are transferred from parents to children and from one generation to another $[1,15]$.

The hypothesis, deriving from the theoretical background, leads us to the following hypothesis:

Hypothesis 1. Albanian National culture has changed over time according to researchers' foreseen results, showing a cultural value score shift toward lower power distance, higher individualism and indulgence and no to small change in masculinity, long-term orientation and uncertainty avoidance.

Hypothesis 2. The difference of institutions does not make any change in the perception of the six dimensions of culture, as they shelter the same national culture.

\section{2. Method}

In this research we have used as a measurement tool Value Survey Module 2013, developed by Hofstede. VSM 2013 is a module, composed from 24 questions that allow measuring the six cultural dimensions (to each dimension corresponds 4 questions), power distance, individualism, masculinity, uncertainty avoidance, long term orientation and indulgence versus restrained [23].

The survey was carried out between June and August 2019 on a representative sample of 387 participants from the two largest private hospitals in Albania, American Hospital and International Hospital Hygeia.

Structured, paper-based, Likert scale questionnaires are our measuring instruments, whereby we aim to reach important conclusions in the cultural dimension field of study. The distribution and the collection of these questionnaires were done manually.

400 paper-based questionnaires were delivered to the staff of the two private Hospitals. 387 questionnaires were collected back with a very good response percentage of 96.75. The participants in this study were part of the medical staff, medical middle and administrative staff of the hospitals. The numbers of respondents correspond to the $20 \%$ of the actual number of employees by each category within these private hospitals.

The questionnaire was constructed in two parts, the demographic part and the cultural dimensions part.

The demographic specifics, related to our research topic, are shown in the following Table $\mathbf{1 .}$

Table 1

Frequency table of participants according their workplace

\begin{tabular}{cccccc}
\hline & Hospital Name & Frequency & Percent & Valid Percent & Cumulative Percent \\
\hline \multirow{4}{*}{ Valid } & International Hospital Hygeia & 119 & 30.7 & 30.7 & 30.7 \\
\cline { 3 - 6 } & American Hospital & 268 & 69.3 & 69.3 & 100.0 \\
& Total & 387 & 100.0 & 100.0 &
\end{tabular}

We must take in consideration that American Hospital is the biggest private hospital in Albania with 370 beds, while International Hospital Hygeia is the second biggest private hospital with 220 beds. Given this fact, the number of participants from these institutions corresponds to their respective size.

Data were analyzed, using descriptive statistics, test statistics of significance, tests of normality Kolmogorov-Smirnov, Shapiro-Wilk, Mann Whitney U test and Kruscal-Wallis test.

\section{Research Results}

Based on the results, collected from the questionnaires, and following the instructions on how to calculate the 6 Dimension indexes that Hofstede has given, we present the descriptive analysis of each dimension.

Findings according to Geert Hofstede's research results show that Albanian National Culture 6 Dimension Score Indexes are as listed below: 
1. Power Distance Index score - 90/100 (High level in Power Distance Index).

2. Individualism Index score- 20/100 (Low in Individualism Index).

3. Masculinity Index score $-80 / 100$ (High Level in Masculinity).

4. Uncertainty Avoidance Index score - 70/100 (High Level in Uncertainty Avoidance).

5. Long-Term Orientation Index score - 61/100 (High Level in Long term Orientation).

6. Indulgence versus Restrained Index score - 15/100 (Low Level in Indulgence, showing a Restrained society).

When we consider the findings of Hofstede about national culture features, we should take in account the difference in time and size of the sample of the population, when given the questionnaire. However a comparative axis can still be build, when we consider the range of the data for every dimension of these national values.

The author of 6 Dimension Matrix of National Values has shown us the path how to reach the result about each dimension by using the following calculation formulas for each dimension.

$$
\begin{aligned}
& \mathrm{PDI}=35(\mathrm{~m} 07-\mathrm{m} 02)+25(\mathrm{~m} 20-\mathrm{m} 23)+\mathrm{C}(\mathrm{pd}) . \\
& \mathrm{IDV}=35(\mathrm{~m} 04-\mathrm{m} 01)+35(\mathrm{~m} 09-\mathrm{m} 06)+\mathrm{C}(\mathrm{ic}) . \\
& \mathrm{MAS}=35(\mathrm{~m} 05-\mathrm{m} 03)+35(\mathrm{~m} 08-\mathrm{m} 10)+\mathrm{C}(\mathrm{mf}) . \\
& \mathrm{UAI}=40(\mathrm{~m} 18-\mathrm{m} 15)+25(\mathrm{~m} 21-\mathrm{m} 24)+\mathrm{C}(\mathrm{ua}) . \\
& \mathrm{LTO}=40(\mathrm{~m} 13-\mathrm{m} 14)+25(\mathrm{~m} 19-\mathrm{m} 22)+\mathrm{C}(\mathrm{ls}) .
\end{aligned}
$$

In the above formulas, given from Hofstede to calculate the indexes for each cultural dimension, $\mathrm{m}$ is the mean score value, each number, following the score values, are the questions corresponding that measure the perceived dimension index and $\mathrm{C}$ is a constant value, the nature of which depends on the nature of the sample and can be chosen to shift scores from 0 to 100 when needed [23].

After explaining the formulas, used to calculate the dimensions' indexes, we calculated the indexes as shown in following Table 2.

Table 2

Descriptive Statistics

\begin{tabular}{lcccccc}
\hline \multicolumn{1}{c}{ Cultural Dimension Index } & N & Range & Minimum & Maximum & Mean & Std. Deviation \\
\hline Power Distance Index (PDI) & 387 & 360.00 & -205.00 & 155.00 & -20.8915 & 69.60133 \\
Individualism Index (IDV) & 387 & 420.00 & -210.00 & 210.00 & -17.4548 & 87.68567 \\
Masculinity Index (MAS) & 387 & 420.00 & -210.00 & 210.00 & 17.1835 & 88.90715 \\
Uncertainty Avoidance Index (UAI) & 387 & 390.00 & -195.00 & 195.00 & 25.0129 & 60.82816 \\
Long Term Orientation Index (LTO) & 387 & 390.00 & -220.00 & 170.00 & -7.7907 & 74.06212 \\
Indulgence versus Restraint Index (IVR) & 387 & 410.00 & -265.00 & 145.00 & -35.8140 & 68.93845 \\
Valid N (listwise) & 387 & & & & &
\end{tabular}

The above table shows the results of the national culture 6 dimension matrix of the data we have collected. Negative and positive mean score values are perceived.

In this study we are not going to compare the findings with another country, we only aim to show the movement of values in time, explained by the data, collected in the research. We test for normality (Table 3). 
Table 3

Tests of Normality

\begin{tabular}{lcccccc}
\hline \multirow{2}{*}{ Cultural Dimension Index } & \multicolumn{3}{c}{ Kolmogorov-Smirnov $^{*}$} & \multicolumn{3}{c}{ Shapiro-Wilk $^{*}$} \\
\cline { 2 - 7 } & Statistic & df & Sig. & Statistic & df & Sig. \\
\hline Power Distance Index (PDI) & 0.115 & 387 & 0.000 & 0.983 & 387 & 0.000 \\
Individualism Index (IDV) & 0.186 & 387 & 0.000 & 0.932 & 387 & 0.000 \\
Masculinity Index (MAS) & 0.220 & 387 & 0.000 & 0.930 & 387 & 0.000 \\
Uncertainty Avoidance Index (UAI) & 0.058 & 387 & 0.004 & 0.993 & 387 & 0.083 \\
Long Term Orientation Index (LTO) & 0.117 & 387 & 0.000 & 0.978 & 387 & 0.000 \\
Indulgence versus Restraint Index (IVR) & 0.100 & 387 & 0.000 & 0.983 & 387 & 0.000
\end{tabular}

Note: * Lilliefors Significance Correction

As we may see from the KS test and ShapiroWilk test ( $\operatorname{sig}<0.05), 5$ dimensions have the nonlinear distribution and only uncertainty avoidance index has the linear one, showing a unanimous perception on the value.

The nonlinear distribution (Table 3) should push the researchers to look in more detailed way the cause of such fluctuations of responses.

As Hofstede advises, to make it easier to comprehend and compare the values we can add a constant value to the mean values in order to have maximum value from 0 to 100 for every dimension. But generally this is a step to take, when two or more national cultures are compared between them. In our case we are trying to see only the Albania's performance and its position according to the values, expressed by the Hofstede survey study. The mean values that we have obtained from the delivered questionnaires show a shift of the values toward more negative or positive ones. This is a well expected situation as [1] and [15] have explained with their research works that through time and with the economic development of the countries the cultural dimensions of country scores will be affected, but still they will stay in the same position in relation to each other as all the countries' value shift together.

Taking into consideration the original work of Hofstede, and adding the replication of the findings, developed by Beugelsdijk et al., (Fig. 1) we are going to give answer to our hypothesis.

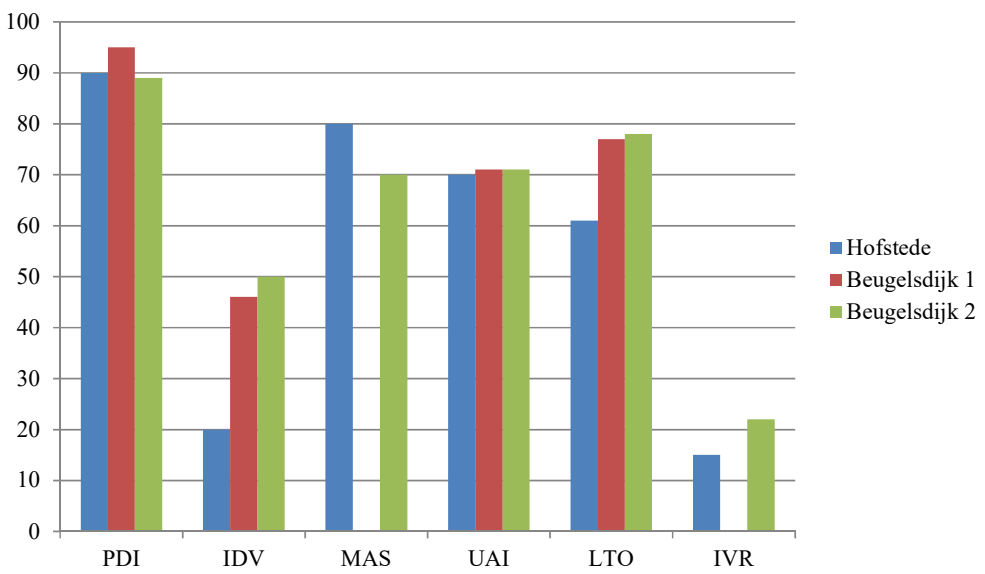

Fig. 1. Cultural Dimension score. Adapted from Hofstede National Culture Survey and Beugelsdijk et al. 2013: - Hofstede national culture survey; - - Beugelsdijk et al. 2013-Cohort 1: Born in 1941; - - Beugelsdijk et al.2013-Cohort 2: Born in 1971

In our research sample measurements as shown in Table 2, the negative mean values of Power Distance Index, equal to -18.84 , show an increase in the perception of power distance di- 
mension. This result is different from the researchers' expectations and prediction, opposing the hypothesis submitted. While researchers have derived values that indicate a decrease in value over time of the PDI, in our sample we perceive a tendency it shows a 110.89 score. This means that the perception of expecting and accepting of inequalities within people of Albania has increased. This result shows that the Albanian environment is dominated by autocratic bosses, where individuals tend to hesitate to express their opinions and express their selves freely.

The Individualism Index with a mean, equal to -17.76 , shows the increase on individualism index demonstrating, an increase in individualism of the society. The Individualism Index (IDV) mean, measured in our research, shows a 37, 45 scores toward individualism. Though still a value that indicates small individualism index, it shows an increasing tendency toward it. This is perceived also in the everyday life of Albanians, where interrelations have become looser than before. Individualism versus Restrained results confirms the hypothesis we have submitted.

The positive mean value result of 15.67 shows that Albania has a tendency toward femininity. The masculinity index, measured in our sample, shows a total score of 62.55 , which positions the country still in the masculine side of the scale, but with a tendency to femininity, a tendency also foreseen from Hofstede in his research work. This kind of change shows that there is an increasing preference of soft, positive values, promoting agreements rather than conflicts.

Another situation is perceived about the Uncertainty Avoidance (UA). The positive mean value, equal to 25.41, brings a decrease of total score of uncertainty Avoidance to 44.99 scores. This shows that people have a greater willingness to take risk than before. About this value Hofstede claims that the direction of its shifting changes in accordance to up and downs of life, politics, economy etc., so our results comply with the foreseen ones and verify the upraised hypothesis.

The negativity of the mean, equal to -7.72 , in Long Term Orientation Index values shows also an increase in this dimension. This means that the country has shifted toward Long Term Orientation with a score of 68.79 scores. This means that Albanians show the tendency to focus more on future results rather than actual outcomes. The increase of long-term orientation, but with a small value, to some extent verifies the hypothesis we submitted. Of course we have to say that researchers predicted a slight to no change for this dimension.

Indulgence versus Restrained Index shows the greatest negative mean value, equal to -38.06 . We see a negative value for Indulgence versus Restraint Index (IVR), which means that the country (sample) has shifted toward Indulgence by 50.81 scores. People have started to enjoy more themselves and do things that make them happy. Supporting the hypothesis submitted and the trend, foreseen by the researchers of the field, the negative value shows an increase in indulgence within the nation. This is a clear indicator that Albanian people show an increasing tendency to value more free time and issues that make them happy rather than only work.

In this part we are supposing that the environment plays a role in the national values. With the data, collected from the questionnaires, we are going to measure such a hypotheses:

$$
\mathrm{H} 0: \mu_{\mathrm{AH}}=\mu_{\mathrm{IHH}},
$$

where $\mu$ represents the vector of 6 variables of national values

$$
\mathrm{H} 1: \mu_{\mathrm{AH}} \neq \mu_{\mathrm{IHH}} \text {. }
$$

From Table 4 we can see differences in these variables, so we need to test if these differences are occasional or statistically significant. For example, IHH has a bigger negative Power Distance Index, comparing with the American Hospital, and also higher Masculinity Index (20.59 vs. 15.67).

As in the question we posed we are trying to test that these differences, showed from the sample, are just random, or they are significant at a $95 \%$ level of confidence.

Since the variables have not a normal distribution after tested for normality, we apply nonparametric tests for two independent group samples, such as Mann Whitney U test. 
Table 4

Group Statistics

\begin{tabular}{cccccc}
\hline Cultural Dimension Index & Institution where you work & N & Mean & Std. Deviation & Std. Error Mean \\
\hline \multirow{2}{*}{ Power Distance Index (PDI) } & International Hospital Hygeia & 119 & -25.50 & 64.851 & 5.945 \\
& American Hospital & 268 & -18.84 & 71.631 & 4.376 \\
Individualism Index (IDV) & International Hospital Hygeia & 119 & -16.76 & 99.815 & 9.150 \\
& American Hospital & 268 & -17.76 & 81.928 & 5.005 \\
Masculinity Index (MAS) & International Hospital Hygeia & 119 & 20.59 & 86.505 & 7.930 \\
& American Hospital & 268 & 15.67 & 90.071 & 5.502 \\
Uncertainty Avoidance Index (UAI) & International Hospital Hygeia & 119 & 24.12 & 66.558 & 6.101 \\
& American Hospital & 268 & 25.41 & 58.231 & 3.557 \\
Long Term Orientation Index (LTO) & International Hospital Hygeia & 119 & -7.94 & 74.650 & 6.843 \\
& American Hospital & 268 & -7.72 & 73.940 & 4.517
\end{tabular}

From the hypothesis test summary we have got the test statistics of significance (Fig. 2), and according to the general rule, we retain as true the null hypothesis if probability (sig) $>0.05$ (allowed error) and reject the null hypothesis if $\operatorname{sig}<0.05$.

Hypothesis Test Summary

\begin{tabular}{|c|c|c|c|c|}
\hline & Null Hypothesis & Test & Sig. & Decision \\
\hline 1 & $\begin{array}{l}\text { The distribution of Power Distance } \\
\text { Index (PDI) is the same across } \\
\text { categories of Institution where you } \\
\text { work. }\end{array}$ & $\begin{array}{l}\text { Independent- } \\
\text { Samples } \\
\text { Mann- } \\
\text { Whitney U } \\
\text { Test }\end{array}$ & .598 & $\begin{array}{l}\text { Retain the } \\
\text { null } \\
\text { hypothesis. }\end{array}$ \\
\hline 2 & $\begin{array}{l}\text { The distribution of Individualism } \\
\text { Index (IDW) is the same across } \\
\text { categories of Institution where you } \\
\text { work. }\end{array}$ & $\begin{array}{l}\text { Independent- } \\
\text { Samples } \\
\text { Mann- } \\
\text { Whitney U } \\
\text { Test }\end{array}$ & .855 & $\begin{array}{l}\text { Retain the } \\
\text { null } \\
\text { hypothesis. }\end{array}$ \\
\hline 3 & $\begin{array}{l}\text { The distribution of Masculinity Inde } \\
\text { (MAS) is the same across } \\
\text { categories of Institution where you } \\
\text { work. }\end{array}$ & $\begin{array}{l}\text { Izdependent- } \\
\text { Samples } \\
\text { Mann- } \\
\text { Whitney U } \\
\text { Test }\end{array}$ & .583 & $\begin{array}{l}\text { Retain the } \\
\text { null } \\
\text { hypothesis. }\end{array}$ \\
\hline 4 & $\begin{array}{l}\text { The distribution of Uncertainty } \\
\text { Avoidance Index (UAl) is the same } \\
\text { across categories of Institution } \\
\text { where you work. }\end{array}$ & $\begin{array}{l}\text { Independent- } \\
\text { Samples } \\
\text { Mann- } \\
\text { Whitney U } \\
\text { Test }\end{array}$ & .733 & $\begin{array}{l}\text { Retain the } \\
\text { null } \\
\text { hypothesis. }\end{array}$ \\
\hline 5 & $\begin{array}{l}\text { The distribution of Long Term } \\
\text { Orientation Index (LTO) is the same } \\
\text { across categories of Institution } \\
\text { where you work. }\end{array}$ & $\begin{array}{l}\text { Independent- } \\
\text { Samples } \\
\text { Guann- } \\
\text { Whitney U } \\
\text { Test }\end{array}$ & .928 & $\begin{array}{l}\text { Retain the } \\
\text { null } \\
\text { hypothesis. }\end{array}$ \\
\hline 6 & $\begin{array}{l}\text { The distribution of Indulgence } \\
\text { versus Restraint Index (IVR) is the } \\
\text { same across categories of } \\
\text { Institution where you work. }\end{array}$ & $\begin{array}{l}\text { Independent- } \\
\text { Samples } \\
\text { Mann- } \\
\text { Whitney U } \\
\text { Test }\end{array}$ & .369 & $\begin{array}{l}\text { Retain the } \\
\text { null } \\
\text { hypothesis. }\end{array}$ \\
\hline
\end{tabular}

Asymptotic signific ances are displayed. The significance level is .05 .

Fig. 2. Hypothesis test Summary

Taking in account this rule we retain the null hypothesis for every dimension of national values by stating that at a $95 \%$ confidence interval, we admit that there are no statistically significant differences in the national values, displayed from the employees of the two organizations. 


\section{Conclusion}

The results of our research show that Albanian National culture has changed over time in most of the cases according to researchers' foreseen results. Negative and positive shift movements have been perceived in the values of cultural values, influenced by various factors in time. The Albanian cultural value score, obtained from our research work, show a shift toward higher power distance, higher individualism, higher indulgence and a small higher change in long-term orientation. On the other hand the cultural value score shows a decrease in masculinity and uncertainty avoidance dimensions' score.

Also the results show that there exists no significant difference in the perception on the cultural dimensions between the two institutions, where the research has been developed.

These results show that Albania embraces of world trends in cultural value shift, and on the other hand proves in the most cases, other that of power distance, that these changes match the expectations of field researchers $[1,15]$.

The statistical analyses have shown that 5 dimensions of culture have the nonlinear distribution (power distance, individualism, masculinity, long term orientation and indulgence) and only uncertainty avoidance index has the linear distribution. These results imply further research regarding the differences of responses and the cause of it in details.

Regarding the results, several implications can be drawn from them. High PDI results, measured in the private hospitals, much higher than the ones, predicted from previous research, show an increase on the perceiving of inequalities. This perception in the healthcare sector in Albania might be the cause of a large number of migrations of medical staff and medical secondary staff in the past years. This problem implies careful reforms that reduce the inequalities in the healthcare sector, including the gap on salaries. The still low but increased levels of IVD show that the individual interest has started to prevail that of masses. Knowing that, institutions can invest more in trainings and programs that highlight the individuality of everyone, at the best benefit of companies. The MAS index of Albania remains still high, showing that the cultural values of the county nurture aggression and conflict in behavior. However the values are softening toward the femininity pole. The UAI is one of the few research results that have taken clear steps toward the opposite pole, taking Albania from a country that is afraid to take risk, to a country that necessarily, as the free market economy expects, is ready to take more risks. People are nowadays more ready for facing the situation of changing jobs, or positions and the county, they have much higher entrepreneurship than before. LTO show a very small movement toward more long term oriented, making Albanians still people who save and think long about the future. Finally the IVR increasing score values show clearly that it is no more sinful to think about being happy and enjoying what you like.

Our research has its limitations as well. The research has been conducted in the biggest private hospitals in Albania. Taking into consideration the uniformity of status and educational level of the sample used, differences between scores of Hofstede's cultural dimensions, where a more general population has been used, and ours are very expected. In future research, for clearer and comprehensive results, the number and type of participants can be multiplied.

\section{References}

[1] Hofstede, G., Hofstede, G. J., Minkov, M. (2010). Cultures and Organizations. Software of the Mind. Intercultural Cooperation and Its Importance for Survival. McGraw-Hill Companies Inc., 561.

[2] Schein, E. H. (2010). Organizational Culture and Leadership. Published by Jossey-Bass, John Wiley \& Sons, Inc., 400.

[3] Nazarian, A., Atkinson, P. (2013). Impact of Culture on Leadership Style: The case of Iranian Organizations. World Applied Sciences Journal, 28 (6), 770-777.

[4] Pfajfar, G., Uhan, M., Fang, T., Redek, T. (2016). Slovenian business culture - How proverbs shape dynamic leadership styles. Journal of East European Management Studies, 21 (4), 433-457. doi: http://doi.org/10.5771/0949-6181-2016-4-433

[5] Dimitrov, K. (2014). Geert Hoftede et al's Set of National Cultural Dimensions - Popularity and Criticisms. Economic Alternatives, 2, 30-60.

[6] Matijevič, S., Raguž, I. V., Filipovič, D. (2015). The Role of National Culture in Contemporary Business Environment, Management and Organization. DIEM 2015. Scientific Conference on Innovation, Leadership and Entrepreneurship. 
[7] Rahj, E., Budak, J., Anic, I. (2015). Hofstede's Culture Survey in Croatia: Examining Regional Differences. Društvena Istraživanja, 25 (3), 309-327. doi: http://doi.org/10.5559/di.25.3.02

[8] Tkeshelashvili, N. (2009).The Effects of Culture on the Leadership Style in Georgia. IBSU Scientific Journal, 3 (2), 115-129.

[9] Daft, R. L. (2010). Organization Theory and design. Ohio: South-Western Cengage Learning, 649.

[10] Bosson, E. K., Boolaky, M., Gungaphul, M. (2016). The Influence of National Culture on Marketing Strategies in Africa. Journal of Business Administration Research, 5 (2), 83-100. doi: http://doi.org/10.5430/jbar.v5n2p83

[11] Sarkar, S., Huang, K. L. (2012). Do cultural groups differ in their attitudes towards unions? Evidence from Indian and Taiwanese samples. Asian Business \& Management, 11 (4), 395-423. doi: http://doi.org/10.1057/abm.2012.5

[12] Peterlin, J., Dimovski, V., Uhan, M., Penger, S. (2014). Integrating stakeholders' multiple intelligences into the leadership development of a cross-cultural entity: Evidence from the CI Ljubjana. Journal of East European Management Studies, 20 (2), $202-225$

[13] Nguyen, A. N. (2016). A Cross-Cultural Study on e-Government Services Delivery. The Electronic Journal Information Systems Evaluation, 19 (2), 121-134.

[14] Rugman, A. M., Collinson, S. (2012). International Business. Pearson Publishing, 800.

[15] Beugelsdijk, S., Maseland, R., Hoorn, A. (2013). Are Hofstede's Culture Dimensions Stable over Time? A Generational Cohort Analysis. doi: http://doi.org/10.2139/ssrn.2336893

[16] Smith, P. B. (2006). When elephants fight, the grass gets trampled: the GLOBE and Hofstede projects. Journal of International Business Studies, 37 (6), 915-921. doi: http://doi.org/10.1057/palgrave.jibs.8400235

[17] Venaik S., Brewer P.; Cantwell, J., Kijak, T. (Eds.) (2008). Contradictions in national culture: Hofstede vs. GLOBE. In Proceedings of the 50th Annual Meeting of the Academy of International Business, 274.

[18] Kirkman, B. L., Lowe, K. B., Gibson, C. B. (2006). A qaurter century of Culture's Consequences: A review of empirical research incorporating Hofstede's Cultural Values framework. Journal of Inernational Business Studies, 37, 285-320. doi: http:// doi.org/10.1057/palgrave.jibs.8400202

[19] Robbins, S. P., Judge, T. A. (2013). Organizational Behavior. Pearson Education Limited, 720.

[20] Tian, K., Borges, L. (2011). Cross-Cultural Issues in Marketing Communications: An Anthropological Perspective of International Business. International Journal of China Marketing, 2, 110-126.

[21] Pires, D. A., Rocha, T. V., Borini, F. M., Rossetto, D. E. (2015). International Marketing in Multinational Company Subsidiaries in Emerging Markets: A Multidimensional Approach. International Marketing in the Fast Changing World, 157-177.

[22] Minkov, M., Hofstede, G. (2012). Hofstede's fifth dimension: New evidence from the World Values Survey. Journal of cross-cultural psychology, 43 (1), 3-14. doi: http://doi.org/10.1177/0022022110388567

[23] Value Survey Module (2013). Available at: https:/geerthofstede.com/

Received date 27.04.2020

Accepted date 25.05.2020

Published date 31.05.2020
(C) The Author(s) 2020

This is an open access article under the CC BY license (http://creativecommons.org/licenses/by/4.0). 